\title{
Emosional Pengguna dalam Mengakses Aplikasi Situs Non Mobile dan MOBILE
}

\author{
Irwansyah \\ Departemen Ilmu Komunikasi FISIP Universitas Indonesia Depok 16424 \\ Pascasarjana STIKOM InterStudi, Indonesia, Jakarta Selatan, 12160 \\ email:dr.irwansyah.ma@gmail.com
}

\begin{abstract}
Emotional side of user toward communication medium should be studied especially about non mobile and mobile site application. Therefore, this research compared emotional user experience while assessing the applications on non mobile and mobile site. This study applied user experience indicators focused on aesthethic visual and interface dimensions. The Equivalent Time-Samples and semantic differential scale were applied. There are nine indicators valid and reliable statistically from 43 of the proposed indicators. T-Test showed that the hypothesis on emotional user experience while accessing the applications on non mobile and mobile site was different and significant. This study also identified that the mobile site is better than non mobile site.
\end{abstract}

Keywords : emotional user experience, non mobile, mobile, site application, visual aesthethic, interfaces.

\begin{abstract}
Abstrak. Sisi emosi pengguna dalam mengakses media komunikasi perlu diamati terutama pada aplikasi situs non mobile dan mobile. Oleh karena itu, penelitian ini membandingkan pengalaman emosional pengguna dalam menggunakan aplikasi situs non mobile dan mobile. Penelitian ini menggunakan konsep pengalaman pengguna dengan memfokuskan pada dimensi estetika visual dan wajah depan aplikasi situs mobile dan non mobile. Dengan desain eksperimen The Equivalent Time-Samples dan skala semantik diferensial menunjukkan terdapat sembilan indikator yang valid dan reliabel dari 43 indikator yang diproposisi. Kemudian uji hipotesis $T$ dependen membuktikan pengalaman emosional pengguna mengakses aplikasi situs non mobile dan mobile memiliki perbedaan dan signifikan. Penelitian ini juga menunjukkan aplikasi situs mobile lebih baik dibandingkan dengan aplikasi situs non mobile.
\end{abstract}

Kata Kunci: pengalaman emosi pengguna, non mobile, mobilesitus aplikasi estetika visual, wajah depan.

\section{Pendahuluan}

Pengalaman menggunakan medium komunikasi mendapat banyak perhatian pada kajian ilmu komunikasi seperti televisi internet (Bernhaupt \& Pirker, 2013). Seiring dengan perkembangan media dan medium komunikasi menuju digital dan ditandai dengan hadirnya situs (website) sebagai salah satu media baru (Straubhaar,
LaRose, \& Davenport, 2012). Kemudian terjadi perubahan terminologi dari pengalaman khalayak (audience experience) menjadi pengalaman pengguna (user experience).

Pengguna merupakan ujung tombak dari perencanaan situs. Chaffey, Ellis-Chadwick, Mayer, dan Johnston (2006) menyatakan bahwa situs yang baik selalu mengawali perencanaannya dengan memahami pengguna. Misalnya 
dengan mengamati cara pengguna dalam memanfaatkan situs. Kemudian mengamati pengalaman pengguna secara online. Apalagi saat ini, situs bertransformasi menjadi aplikasi situs mobile (mobile site apps). Akibatnya, sebagai suatu salah satu produk media baru, aplikasi situs mobile membutuhkan tampilan visual awal yang kompetitif untuk mendapatkan pengalaman yang positif (Garrett, 2011). Penataan ulang menjadi penting untuk dapat memberikan pengalaman user-friendly bagi orang-orang yang mengakses (M2 Presswire, 2012). Pengamatan terhadap pengalaman pengguna mengakses situs menarik dilakukan karena situs baik statis maupun berbasis aplikasi mobile merupakan potongan-potongan teknologi yang kompleks. Malah terkadang orang-orang menyalahkan dirinya sendiri ketika bermasalah menggunakan potongan teknologi tersebut (Garrett, 2011). Akhirnya pengguna seringkali merespon pengalaman terhadap situs secara irasional (Garrett, 2011) dan emosional (Zymbalis, Theodorou, \& Pavlakis, 2008).

Pengalaman emosional pengguna merupakan strategi sukses situs (M2 Presswire, 2003). Pengalaman yang dirasakan pengguna merupakan indikator berhasil atau gagalnya aplikasi situsnya di pasaran (Meyer \& Schwager, 2007). Kegagalan situs seringkali terjadi karena dikelola secara tidak profesional dan memberikan pengalaman buruk kepada pengguna (Crayons, 2011). Sebaliknya pengalaman pengguna menjadi positif seiring dengan akibatnya pada sikap pengalaman terhadap aplikasi situs (Meyer \& Schwager, 2007). Dalam konteks komunikasi, pengalaman pengguna terjadi pada saat menerima pesan baik berbentuk teks dan visual dari suatu situs dan aplikasi mobile (Coloma, 2012). Pengalaman menggunakan aplikasi situs berbasis statis ataupun berbasis mobile merupakan respon pengguna terhadap pemenuhan informasi yang dibutuhkannya (Noelle-Levitz, 2005). Sehingga situs disadari sebagai medium baru yang berfungsi mendistribusikan informasi (Garrett, 2011). Bahkan saat ini, masyarakat cenderung memanfaatkan situs dan berbagai aplikasi mobile sebagai sumber utama informasi (Williamson, Lepak, \& King, 2003).

Kajian mengenai pengalaman emosional pengguna mengakses situs lebih banyak dikaitkan dengan aspek teknis, seperti usabilitas (ShrimptonSmith \& Zaman, 2007; Petrie \& Precious, 2010; Joshi \& Avasthi, 2007). Hal ini menunjukkan penelitian pengalaman pengguna masih berada pada level teknis yang hanya dipahami oleh pembuat atau level pakar. Pengalaman pengguna terbentuk dari serangkaian interaksi pengguna dengan wajah depan (interface) (Agarwal \& Meyer, 2009), dan estetika desain (Bernhaupt \& Pirker, 2013; Tarrant, 2007). Tarrant (2007) juga menyatakan estetika visual dapat mempengaruhi perasaan emosional pengguna. Apalagi saat ini situs berevolusi dari statis menuju dinamis. Selain mengadopsi berbagai fitur dan berevolusi menjadi lebih interaktif, situs juga berevolusi berdasarkan perangkat yang digunakan untuk mengakses (Roto, 2006).

Situs yang diakses melalui perangkat mobile menarik diamati karena tiga hal. Pertama, internet berisi informasi penting bagi kehidupan sehari-hari yang mulai banyak diakses perangkat mobile dan aplikasi mobilenya. Pengguna perangkat mobile dengan aplikasinya terus meningkat karena harga perangkat mobile yang cenderung 
semakin murah, tersedianya jaringan internet secara luas (eTForecasts, 2006). Ipsos Insight (2006) juga menyatakan bahwa perangkat mobile akan menjadi platform internet. Pernyataan Ipsos Insight didukung fakta yang menyatakan pertumbuhan user perangkat mobile mencapai 5,3 milyar user pada tahun 2012, dan $73 \%$ diantaranya tumbuh pada negara berkembang (Swinton \& Kaliouby, 2012).

Kedua, kajian pengguna yang dapat diaplikasikan pada perangkat mobile memperlihatkan pengguna tetap menginginkan tampilan layar penuh suatu situs (Kaasinen, 2005). Ketiga, perangkat mobile menduduki posisi yang kuat dalam menyelesaikan pekerjaan (Roto, 2006). Roto lebih lanjut menyatakan bahwa display perangkat mobile saat ini berkualitas tinggi dengan lebih banyak pixel dan kontras yang baik. Apalagi pada perangkat mobile juga didukung fitur koneksi internet, sehingga akses situs melalui perangkat mobile semakin baik dari segi tampilan maupun konten.

Walaupun tampilan dan konten situs pada perangkat mobile tidak berbeda dengan perangkat desktop ataupun laptop. Sehingga format situs berbasis statis berbeda dengan mobile secara teknis berbeda. Website statis atau pada perangkat non mobile menggunakan format HTML, sedangkan situs pada perangkat mobile (mobile website) menggunakan Wireless Markup Language (WML), Compact HTML (C-HTML), atau (X)HTML (Timmins, McCormick, Agu, \& Wills, 2006). Timmins, McCormick, Agu dan Wills selanjutnya menyatakan bahwa format mobile website yang berbeda ini dapat dilihat dari URL situs dengan menambahkan huruf ' $m$ ' (yang berarti mobile) sebelum nama situs ketika diakses menggunakan perangkat mobile. Kemudian, Kaasinen dkk (2009) juga menyatakan perangkat mobile memiliki batasan menampilkan konten website. Kaasinen dkk lebih lanjut menambahkan tampilan website yang terlalu kompleks dan rumit akan sulit ditampilkan pada perangkat mobile dan terdapat fitur yang tidak bisa dibuka seperti suara dan video.

Perbedaan format situs pada perangkat mobile membawa perubahan cara mengakses (Kaasinen, et al., 2009). Kaasinen (2005) menyatakan bahwa ketika pengguna bergerak, pengguna menggunakan layanan yang menyediakan keperluan, komunikasi dan kesenangan. Sellen dan Murphy (2002) selanjutnya juga menyatakan user yang menggunakan mobile website cenderung memanfaatkannya untuk kepentingan browsing dan menemukan informasi sembari mengisi waktu luang. Sedangkan untuk mengumpulkan informasi, pengguna cenderung mengumpulkan data dengan kapasitas yang kecil dan tidak memakan waktu lebih dari 20 menit ketika mengakses situs pada perangkat mobile (Sellen \& Murphy, 2002). Perubahan cara mengakses website pada perangkat mobile juga berpengaruh pada pengalaman user terhadap mobile website (Neerincx \& Streefkerk, 2003). Sayangnya, studi pengalaman pengguna mengenai mobile website saat ini masih didominasi oleh pendekatan teknis, sama seperti pengalaman pengguna pada situs di perangkat non mobile. Pengalaman user mengakses website pada perangkat mobile dari sisi teknis lebih banyak menyoroti tentang usabilitas (Roto, 2006; Kaikkonen, 2009), layanan dan infrastruktur mobile website (Kaasinen, et al., 2009), penerimaan mobile website di masyarakat (Kaasinen E. , 2005; Lu, Liu, Yu, \& Wang, 2008). Padahal, mobile website sebagai teknologi interaktif tidak cukup dilihat dari pendekatan teknis saja seperti manfaat 
dan usabilitas (Zimmermann, 2008). Hal ini dapat dilihat dengan mengukur emosional (Logan, 1994) dan kesenangan (Jordan, 2000; Hassenzahl, 2001) pengguna. Pengukuran respon emosional yang pernah dilakukan masih berbicara mengenai variabel yang berkontribusi pada terbentuknya pengalaman emosional user yang tergantung pada konteks kondisi pengguna (Zimmermann, 2008; Joshi \& Avasthi, 2007). Agar lebih obyektif respon emosional membutuhkan skala pengukuran (Swinton \& Kaliouby, 2012). Pengukuran pengalaman pengguna terutama pada level emosional juga masih dilakukan dengan melihat pada masing-masing perangkat pengakses website seperti PC atau pada perangkat mobile saja. Oleh karena itu, studi ini berusaha mengkomparasikan respon emosional user dalam mengakses situs pada perangkat non mobile dan mobile. Sehingga, perumusan masalah pada penelitian ini adalah: Bagaimana perbandingan pengalaman emosional yang dialami pengguna dalam mengakses situs melalui perangkat non-mobile dan mobile?

\section{Kerangka Konseptual}

Berdasarkan ISO 9241-11, pengalaman pengguna (user experience) merupakan keseluruhan aspek pengalaman pengguna ketika berinteraksi dengan produk termasuk usabilitas dan sifat disukai (desirability) berdasarkan perspektif pengguna (ISO, 1998). Pada ISO tersebut, usabilitas juga dijelaskan sebagai kepuasan pengguna (Zimmermann, 2008). Namun pengalaman pengguna tidak hanya mencakup usabilitas. Rudnicka (2011) mencatat setidaknya terdapat empat peran pengalaman pengguna yaitu (1) mentransfer emosi kepada pengguna, (2) menciptakan kepuasan pengguna,
(3) mengikat pengguna, dan (4) menciptakan kesan kepada pengguna. Pengalaman pengguna tidak cukup dibangun dengan nilai rasional seperti usabilitas saja, tetapi juga membutuhkan nilai emosional (Chaffey, Ellis-Chadwick, Mayer, \& Johnston, 2006). Untuk menciptakan pengalaman pengguna, dibutuhkan nilai rasional, nilai emosional dan pengalaman yang dijanjikan pada suatu situs (Chernatony, 2001). Nilai rasional terbagi menjadi tiga dimensi yaitu kemudahan menggunakan, relevansi dan performa. Hal-hal terkait teknis situs seperti usabilitas, aksesibilitas, konten dan pencarian, kustomisasi, kecepatan dan ketersediaan, termasuk dalam nilai-nilai rasional pengalaman pengguna. Sedangkan nilai emosional mencakup desain visual dan kepastian (Chaffey, Ellis-Chadwick, Mayer, \& Johnston, 2006). Goddard, McLeary, dan Gorney (2008) juga memberikan pemahaman alternatif pengalaman pengguna melalui lima dimensi yaitu (1) usaha, (2) usabilitas, (3) kekuatan dan kegunaan, (4) persuasi dan (5) merek.

Pengalaman pengguna merupakan evaluasi konsumen terhadap produk yang lebih mengutamakan perasaan baik atau buruk (Hassenzahl, 2001). Pendekatan yang dikemukakan Hassenzahl tersebut menyatakan reaksi atau respon pengguna terhadap situs lebih didominasi reaksi emosional daripada reaksi kognitif. Perbandingan respon emosional pengguna mengakses situs pada perangkat non mobile dan mobile belum banyak mendapat perhatian para peneliti. Perbandingan yang pernah dilakukan berusaha mengukur emosi pengguna dilihat dari usabilitas (Roto, 2006; Kaikkonen, 2009) sebagai aspek teknis website. Oleh karena itu penelitian ini mengeksplorasi komparasi pengalaman emosional pengguna dalam mengakses 
suits melalui perangkat non mobile dan mobile. Sehingga, hipotesis penelitian adalah sebagai berikut:

$H_{o} \quad$ : Terdapat perbedaan pengalaman emosional pengguna dalam mengakses website melalui perangkat non mobile dan mobile.

Menurut Roto (2006) tampilan situs pada perangkat mobile yang berbentuk miniatur dari situs layar besar (non mobile) menarik diamati. Hal ini dikarenakan desain situs pada layar besar mengalami transformasi pada perangkat mobile yang berlayar kecil sesuai dengan format aplikasi situs yang digunakan (Timmins, McCormick, Agu, \& Wills, 2006). Sehingga penelitian ini lebih berfokus pada perbedaan pengalaman emosional pengguna berdasarkan aspek estetika visual (Bernhaupt \& Pirker, 2013; Tarrant, 2007) dan antar wajah (Agarwal \& Meyer, 2009) non mobile dan mobile website.

\section{Metodologi}

Pengalaman pengguna merupakan perasaan saat berinteraksi dengan teknologi tertentu (Kaasinen, et al., 2009). Sedangkan, emosi yang dirasakan pengguna merupakan respon dari situasi mengakses situs yang memungkinkan diadakannya evaluasi pengukuran (Zimmermann, 2008). Sehingga pengalaman pengguna dapat diukur secara obyektif (Sauro \& Lewis, 2012) dan dapat memprediksi perilaku atau tujuan perilaku berikutnya (Deng, Turner, Gehling, \& Prince, 2010). Penelitian ini mengukur konsep estetika visual (Tarrant, 2007) dan antar muka situs (Agarwal \& Meyer, 2009) sebagai variabel yang berkontribusi terhadap pengalaman emosional pengguna dengan menggunakan metode eksperimen.

Seltman (2013) mengatakan metode eksperimen merupakan metode yang paling tepat untuk mengukur suatu konsep secara ilmiah. Metode eksperimen dikatakan dapat menghasilkan reliabilitas dan validitas yang tinggi. Metode eksperimen juga dapat menghindari bias dan lebih praktis (Seltman, 2013). Oleh karena itu, penelitian ini menggunakan metode eksperimen yang mengukur estetika visual dan antar muka situs dengan membandingkan pengalaman emosional pengguna dalam mengakses aplikasi situs pada perangkat non mobile dan mobile.

Karena metode eksperimen juga merupakan metode yang secara spesifik cenderung digunakan untuk menganalisis isu dalam ruang lingkup atau skala kecil (Neuman, 2006). Maka, penelitian ini memberikan perlakuan berbeda kepada kelompok partisipan dengan membandingkan pengalaman emosional pengguna mengakses situs. Untuk mengamati perbedaan pengalaman emosional pengguna, dua perlakuan berbeda diberikan kepada partisipan yaitu mengakses aplikasi situs melalui (1) perangkat non mobile seperti desktop atau personal computer (PC) dan (2) perangkat mobile seperti smartphone atau tablet.

Penelitian ini menggunakan desain penelitian eksperimen The Equivalent Time-Samples Design untuk melakukan pengukuran perbedaan pengalaman emosional antara aplikasi situs non mobile dan mobile. Desain penelitian ini termasuk dalam quasi experimental design karena tidak melakukan pretest dan kelompok kontrol (Campbell \& Stanley, 1963). Dikatakan bahwa The Equivalent TimeSamples Design merupakan desain penelitian yang biasa digunakan untuk membandingkan sampel yang sepadan. Sebelum melakukan uji eksperimen, diperlukan perencanaan dan mengantisipasi penjelasan alternatif 
atau permasalahan validitas internal (Neuman, 2006).

Pemilihan subyek penelitian atau partisipan dilakukan dengan randomisasi (Babbie, 2004). Randomisasi dimulai dengan pengumpulan partisipan secara sukarela. Hal ini pernah dilakukan oleh Sundar (1998) dengan mengajak mahasiswa berpartisipasi secara sukarela pada eksperimen pengukuran persepsi terhadap situs berita online. Pengumpulan partisipan dilakukan dengan menyebarkan undangan partisipan di media sosial. Undangan menjadi partisipan disampaikan melalui media sosial (Facebook, Twitter, Instagram, Google+ dan Blog). Selain melalui media sosial, undangan menjadi partisipan juga disampaikan melalui milis. Partisipan yang terpilih harus memenuhi persyaratan yang telah ditentukan. Pertama memiliki perangkat mobile baik itu smartphone atau tablet/pad. Kedua, partisipan pernah mengakses aplikasi melalui perangkat non mobile dan mobile dalam kurun waktu seminggu terakhir (Irwansyah, 2015). Pada saat pendaftaran, calon partisipan diminta mengisi form mengenai aplikasi yang paling sering diakses pada perangkat non mobile dan mobile, data demografi partisipan dan spesifikasi kepemilikan perangkat mobile. Jawaban calon partisipan selanjutnya menentukan situs yang menjadi perlakuan pada saat eksperimen. Kemudian, calon partisipan yang dipilih merupakan partisipan yang memiliki kemiripan spesifikasi perangkat mobile seperti tipe perangkat, ukuran layar, dan operating system (OS). Selanjutnya, calon partisipan hasil penyaringan perangkat mobile dilakukan pengacakan (random assignment) untuk terpilih menjadi partisipan eksperimen sebanyak 30 orang, karena jumlah ideal dalam setiap kelompok eksperimen pada sisi pengguna situs minimal 30 partisipan (Leroy, 2011).

Kemudian partisipan yang terpilih diberi undangan keterlibatan eksperimen pada tanggal dan lokasi yang telah ditentukan. Lokasi penelitian ini berkapasitas 30 orang. Ruangan eksperimen dilengkapi perangkat pengakses aplikasi situs berbasis non mobile dan mobile. Perangkat non mobile berupa desktop atau PC dan perangkat mobile berupa smartphone atau tablet/pad (Roto, 2006). Standar perangkat desktop menggunakan Intel Pentium, 2,8 GHz, $512 \mathrm{Mb}$ RAM, Microsoft Windows XP Operating System, monitor 15", dimensi layar 600x800, kontras dan kecerahan layar diatur pada level optimal (Schaik \& Ling, 2008). Sedangkan perangkat mobile, partisipan disyaratkan membawa sendiri smartphone atau tablet/pad yang dimiliki. Spesifikasi perangkat mobile yang digunakan adalah smartphone dengan tipe Android, I-Pad, Galaxy Tab, dan Playbook (Kontan, 2011). Kemudian, ruangan eksperimen juga dilengkapi koneksi internet untuk mengakses aplikasi situs.

Situs yang diakses ditentukan pada proses rekruitmen partisipan dengan memilih situs yang paling sering diakses partisipan pada perangkat non mobile dan mobile. Kemudian pengumpulan data pada penelitian eksperimen ini menggunakan instrument kuesioner yang berisi item pertanyaan pengalaman emosional user. Teknik pengumpulan data menggunakan kuesioner pada penelitian eksperimen pernah dilakukan Tarrant (2007), Zimmermann (2008), dan Hundley (2009) untuk mengukur pengalaman pengguna pada level emosional. Berdasarkan item pertanyaan yang diajukan, instrument kuesioner 
penelitian terbagi menjadi tiga bagian. Bagian pertama berisi data demografis dan pertanyaan mengenai kebiasaan partisipan mengakses situs. Data demografis yang ditanyakan adalah identitas personal, sedangkan pada penggunaan media mengekplorasi tipe gadget dan frekuensi mengakses situs (Bernhaupt \& Pirker, 2013). Bagian pertama kuesioner ini sekaligus menjadi form pendaftaran bagi calon partisipan penelitian eksperimen.

Bagian kedua berisi surat persetujuan (consent form) partisipan atas kesediaan mengikuti penelitian eksperimen secara sukarela. Selain itu surat pernyataan yang menunjukkan bahwa eksperimen yang dilakukan tidak akan mempengaruhi atau menyebabkan perubahan emosi secara langsung. Sebelum menandatangani lembar pernyataan kesediaan, partisipan diberikan penjelasan tentang maksud dan tujuan dari penelitian yang dimaksud (Irwansyah, 2015).

Bagian ketiga kuesioner berisi pertanyaan mengenai pengalaman emosional pengguna yang diukur dari dua variabel yaitu estetika visual (Tarrant, 2007) dan antarmuka situs (Agarwal \& Meyer, 2009). Estetika visual terdiri dari 30 indikator yaitu: (1) kemenarikan (tidak menarik vs menarik); (2) keseimbangan (tidak seimbang vs seimbang); (3) kecerahan (buram vs cerah); (4) ketenangan (gaduh vs tenang); (5) klasik (tidak klasik vs klasik); (6) penuh warna (monoton vs penuh warna); (7) keringkasan (tidak ringkas vs ringkas); (8) konvensional (konvensional vs modern); (9) keelokan (tidak elok vs elok); (10) kemewahan (tidak mewah vs mewah); (11) elegan (tidak elegan vs elegan); (12) keakraban (tidak akrab vs akrab); (13) kesegaran (tidak segar vs segar); (14) futuristik (tidak futuristik vs futuristik); (15) penuh harapan (tidak ada harapan vs penuh harapan); (16) mistis (tidak mistis vs mistis); (17) datar (datar vs tidak datar); (18) populer (tidak populer vs populer); (19) kekuatan (tidak ada kekuatan vs penuh kekuatan); (20) menjanjikan (tidak menjanjikan vs menjanjikan); (21) seksi (tidak seksi vs seksi); (22) ketajaman (tidak tajam vs tajam) (23) sederhana (tidak sederhana vs sederhana); (24) statis (statis vs dinamis); (25) kuat (lemah vs kuat); (26) surealis (tidak surealis vs surealis); (27) ketegangan (tidak tegang vs tegang); (28) kesamaran (samar vs jelas); (29) berharga (tidak berharga vs berharga); dan (30) bersemangat (tidak bersemangat vs bersemangat).

Sedangkan antar muka situs dapat diukur dari 13 pasang kata sifat bipolar (Agarwal \& Meyer, 2009) yaitu (1) keramahan (tidak ramah vs ramah), (2) gangguan (mengganggu vs menyenangkan), (3) kepuasan (tidak puas vs puas), (4) harapan (putus asa vs penuh harapan), (5) ketegangan (tegang vs tidak tegang), (6) stimuli (santai vs stimuli), (7) semangat (tenang vs semangat), (8) kesadaran (mengantuk vs sadar), (9) kemunculan (tenggelam vs muncul), (10) kendali (mengendalikan vs dikendalikan), (11) pengaruh (dipengaruhi vs berpengaruh), (12) dominasi (patuh vs dominan), dan (13) otonomi (memandu vs otonomi).

Dalam penelitian eksperimen, teknik analisis data dikenal dengan sebutan Exploratory Data Analysis (EDA) (Seltman, 2013). Analisis komparasi menggunakan teknik statistik uji $\mathrm{T}$ (T-test ) untuk membandingkan dua perlakuan yang berbeda (Larson \& Farber, 2012). Uji T digunakan karena jumlah $\mathrm{N}$ atau partisipan kurang dari 30 orang dengan sampel acak dan data interval (Malhotra, 2004). Selanjutnya teknik uji $\mathrm{T}$ menggunakan paired samples-one tailed karena penelitian ini melihat dua variabel berbeda pada kelompok partisipan yang sama 
(Malhotra, 2004). Perbedaan yang dilihat adalah pengalaman emosional partisipan mengakses aplikasi situs melalui perangkat non mobile dan mobile.

Analisis komparasi statistik yang digunakan ini sekaligus menjawab hipotesis penelitian, sehingga uji $\mathrm{T}$ digunakan untuk menjawab hipotesis statistik sebagai berikut:

$\mathrm{H}_{0}: \mu_{\mathrm{nm}}=\mu_{\mathrm{m}}$

$\mathrm{H}_{\mathrm{a}}: \mu_{\mathrm{nm}} \neq \mu_{\mathrm{m}}$ (claim)

Keterangan :

$\mu_{\mathrm{nm}}$ : nilai mean pengalaman emosional pengguna mengakses aplikasi situs pada perangkat non mobile.

$\mu_{\mathrm{m}}$ : nilai mean pengalaman emosional pengguna mengakses aplikasi situs pada perangkat mobile.

Dalam penelitian eksperimen, pengujian validitas internal dan eksternal (Neuman, 2006) digunakan untuk mengukur kemampuan desain eksperimen sekaligus menjelaskan hubungan kausalitas antara variabel independen dan variabel dependen. Oleh karena itu perlu diadakan pilot-test terlebih dahulu (Neuman, 2006) untuk melakukan validitas internal. Validitas internal pada penelitian eksperimen ini yang perlu diperhatikan terkait dengan efek maturasi, historis dan tes (testing effect). Hal ini dikarenakan penelitian ini menggunakan desain The Equivalent Time-Samples Design yang tidak mengukur kelompok kontrol dan melakukan pre-test. Kemudian adanya dua perlakuan juga dikhawatirkan menyebabkan efek maturasi yang menyebabkan partisipan jenuh ketika mengisi kuesioner kedua (Altermatt, 2014). Perangkat mobile yang digunakan partisipan yang berasal dari kepemilikan pribadi dan mengakses situs yang paling sering diakses juga dikhawatirkan terjadi efek historis. Hal ini dikarenakan partisipan mengasumsikan pengalaman terdahulu dan kebiasaan mengakses perangkat mobile yang dimiliki ketika mengisi kuesioner (Altermatt, 2014). Desain penelitian yang mengarahkan partisipan mengalami dua perlakuan berbeda pada waktu yang berdekatan juga dikhawatirkan terjadi efek tes (testing effect) yaitu partisipan membandingkan dan terpengaruh dari perlakuan pertama (Altermatt, 2014).

Kemudian, untuk validitas eksternal digunakan untuk mengukur temuan eksperimen dapat digeneralisasi terhadap kejadian atau situasi diluar eksperimen (Neuman, 2006), maka perlu disadari adanya realism dan reaktivitas (reactivity). Penelitian ini melakukan experimental realism agar eksperimen sesuai dengan keadaan realistis, sehingga eksperimen dapat memberikan pengaruh nyata terhadap partisipan berusaha (Neuman, 2006). Sedangkan untuk mencegah reaktivitas yang berlebihan, partisipan tidak diperkenankan berkomunikasi selama eksperimen berlangsung. Kontak yang terjadi diantara partisipan dikhawatirkan menyebabkan partisipan mengetahui tujuan eksperimen dan partisipan mengubah perilaku sesuai dengan tujuan tersebut (demand characteristics) (Neuman, 2006). Sehingga pemilihan partisipan secara acak juga diharapkan dapat mencegah bias seleksi yang dapat menyebabkan efek interaksi antar partisipan. Pemilihan secara acak juga diharapkan dapat terpilihnya representatif populasi secara umum sehingga dapat digeneralisasi.

Selanjutnya, validitas data dilakukan dengan dengan dua cara yaitu pertama, validitas isi (content validity) yaitu melihat hasil skala item yang dihasilkan dari tiga variabel yang diamati dalam uji bipolar menggunakan 
tes KMO dan Bartlett Test of Sphericity. Kedua, dengan validitas konsep (concept validity) dengan merujuk kembali kepada konsep dan teori yang digunakan dalam literatur. Sedangkan reliabilitas dengan menghitung Alpha's Cronbach pada skala item yang dihasilkan uji bipolar. Selanjutnya dilakukan analisis faktor yang bersifat eksploratori (EFA) untuk melihat pengelompokkan berdasarkan dimensi variabel konten. EFA juga digunakan untuk mereduksi indikator-indikator yang tidak valid (Field, 2000; Douglas, 2008). Setelah melalui kedua uji ini, dilakukan analisis faktor sebagai bentuk analisis lanjutan yang melihat ekstraksi faktor-faktor yang terbentuk.

\section{Temuan dan Diskusi}

Pengukuran konsistensi internal dan kecukupan sampel menunjukkan dimensi estetika visual dan antar muka situs valid secara statistik dan dapat dilakukan analisis faktor. Berdasarkan analisis faktor, terbentuk satu dimensi baru menggabungkan kedua dimensi yang menjadi pengukuran pada respon pengalaman emosional terhadap situs. Sehingga dimensi baru yang terbentuk terdiri dari sembilan indikator yang berasal dari kedua dimensi.

Perubahan dimensi tersebut dipengaruhi karena adanya indikator yang direduksi. Beberapa validitas dan konsistensi internal indikator menyebabkan nilai KMO dan Bartlett Test rendah. Setelah indikator direduksi, dilakukan analisis faktor. Sebelum melakukan analisis faktor terdapat beberapa hal yang harus diperhatikan. Pertama, Bartlett Test of Sphericity untuk melihat keterkaitan indikator dalam suatu variabel. Kedua, KaiserMeyer Olkin Measure of Sampling Adequacy (KMO) untuk melihat kecukupan sampel (Kaiser, 1974). Nilai kecukupan $\mathrm{KMO} \geq 0,5$ mengindikasikan data tersebut dapat dilanjutkan dengan analisis faktor (Field, 2000).

Dengan demikian, semua dimensi baru yang diobservasi dianggap valid karena nilai KMO lebih dari 0,5 (Field, 2000). Kemudian pengujian Bartlett dengan tingkat signifikansi statististik $\mathrm{p}<0,0005$ dengan koefisien degree of freedom (df) tidak nol, maka dimensi yang diobservasi dianggap memuaskan. Kemudian tahap selanjutnya adalah menentukan faktor. Menurut Malhotra (2007), penentuan faktor berdasarkan nilai eigenvalue yang lebih dari satu. Nilai eigenvalue yang kurang dari 1.0 tidak dimasukkan ke dalam model penelitian. Eigenvalue juga mewakili total dari seluruh nilai variasi yang berhubungan dengan faktor yang terbentuk.

Selanjutnya pada hasil uji reliabilitas menurut Alpha's Cronbach memperlihatkan bahwa sembilan indikator yang valid tersebut terbukti reliabel dan tidak perlu direduksi lagi. Uji reliabilitas merupakan uji konsistensi internal kuesioner (Cronbach, 1984). Indeks alpha ( $\alpha)$ merupakan indeks terpenting dari konsistensi internal dan diatribusikan sebagai rata-rata korelasi pada seluruh variabel (Anastasiadou, 2006). Angka koefisien Alpha's Cronbach dianggap memadai dan dapat dikatakan baik, apabila nilai koefisien lebih besar dari angka 0,6 (Malhotra, 2007). 
Reliability Statistics

Tabel 1. Hasil Uji Reliabilitas

\begin{tabular}{|r|r|}
\hline Cronbach's Alpha & N of Items \\
\hline .884 & 9 \\
\hline
\end{tabular}

Item-Total Statistics

\begin{tabular}{|l|r|r|r|r|}
\hline & $\begin{array}{l}\text { Scale Mean if } \\
\text { Item Deleted }\end{array}$ & $\begin{array}{l}\text { Scale Variance } \\
\text { if Item Deleted }\end{array}$ & $\begin{array}{l}\text { Corrected Item- } \\
\text { Total Correlation }\end{array}$ & $\begin{array}{l}\text { Cronbach's Alpha } \\
\text { if Item Deleted }\end{array}$ \\
\hline D1 & 40.95 & 60.323 & .660 & .861 \\
D2 & 41.16 & 62.137 & .599 & .866 \\
D3 & 40.59 & 62.247 & .542 & .874 \\
D12 & 40.39 & 65.545 & .574 & .870 \\
D13 & 40.55 & 60.533 & .650 & .862 \\
D22 & 41.05 & 60.230 & .568 & .874 \\
D29 & 40.86 & 66.865 & .568 & .874 \\
E1 & 40.43 & 62.763 & .681 & .862 \\
E3 & 40.93 & 60.763 & .661 & .862 \\
\hline
\end{tabular}

Uji Alpha's Cronbach's menghasilkan angka 0.884 dan pada kolom Cronbach's Alpha if Item Deleted menunjukkan tidak ada indikator yang perlu direduksi. Angka 0.884 juga memperlihatkan semua indikator memiliki reliabilitas yang tinggi, karena nilai 0.7-0.9 menunjukkan high reliability (Hinton, Brownlow, McMurray, \& Cozens, 2004; Dwivedi, Choudrie, \& Weerakkody, 2006). Oleh karena itu terdapat sembilan indikator yang teruji validitas dan reliabilitasnya berdasarkan uji statistik yaitu indikator dengan kode D1 (tidak menarik-menarik), D2 (tidak seimbang-seimbang), D3 (tidak cerahcerah), D12 (tidak akrab-akrab), D13 (tidak segar-segar), D22 (tidak tajamtajam), D29 (tidak berharga-berharga), E1 (tidak ramah-ramah) dan E3 (tidak puas-puas). Selanjutnya kesembilan indikator ini dapat dilanjutkan pada tahap analisis komparatif untuk melihat adanya perbedaan pengalaman emosional pengguna mengakses aplikasi situs pada perangkat non mobile dan mobile.

Pengujian hipotesis dilakukan dengan uji $\mathrm{T}$ untuk menguji adanya perbedaan diantara kedua sampel.

Paired Samples Test

Tabel 2. Hasil Uji T dependen

\begin{tabular}{|c|c|c|c|c|c|c|c|c|}
\hline & \multicolumn{5}{|c|}{ Paired Differences } & \multirow[t]{3}{*}{$t$} & \multirow[t]{3}{*}{$\mathrm{df}$} & \multirow{3}{*}{$\begin{array}{l}\text { Sig. } \\
(2- \\
\text { tailed })\end{array}$} \\
\hline & \multirow[t]{2}{*}{ Mean } & \multirow[t]{2}{*}{$\begin{array}{l}\text { Std. } \\
\text { Deviati } \\
\text { on }\end{array}$} & \multirow[t]{2}{*}{$\begin{array}{l}\text { Std. } \\
\text { Error } \\
\text { Mean }\end{array}$} & \multicolumn{2}{|c|}{$\begin{array}{l}95 \% \text { Confidence } \\
\text { Interval of the } \\
\text { Difference }\end{array}$} & & & \\
\hline & & & & Lower & Upper & & & \\
\hline $\begin{array}{ll}\text { Pair } & \text { Mean_NM - } \\
1 & \text { Mean_M }\end{array}$ & $\begin{array}{r}.4545 \\
5\end{array}$ & $\begin{array}{r}1.0501 \\
3\end{array}$ & $\begin{array}{r}.2238 \\
9 \\
\end{array}$ & -.01106 & .92015 & $\begin{array}{r}2.03 \\
0\end{array}$ & 21 & .000 \\
\hline
\end{tabular}


Berdasarkan tabel diatas mengenai hasil uji $\mathrm{T}$ dependen sampel, nilai $\mathrm{p}$ yang ditunjukkan pada kolom Sig. (2-tailed) adalah $\alpha$ yaitu 0.00 , atau $\mathrm{p}<0,05$. Sehingga kedua sampel berbeda secara signifikan. Artinya pengalaman emosional pengguna mengakses aplikasi situs pada perangkat non mobile dan mobile dapat dianggap berbeda berdasarkan uji $\mathrm{T}$ dependen. Uji T dependen juga sekaligus menguji hipotesis yang menyatakan Ho ditolak karena nilai $\mathrm{p}<0,05$. Sehingga hipotesis yang diterima berdasarkan uji statistik adalah terdapat perbedaan pengalaman emosional pengguna mengakses aplikasi situs pada perangkat non mobile dan mobile.

Penelitian ini mengukur pengalaman emosional pengguna berdasarkan pendekatan non teknis yang dilihat dari estetika visual dan antar muka. Analisis komparasi pengalaman emosional pengguna mengakses situs, menggunakan sembilan indikator yang telah teruji valid dan reliabel secara statistik. Sembilan indikator ini tergabung dalam satu dimensi estetika visual \& antarmuka situs yang merupakan gabungan dari dimensi sebelumnya; dimensi estetika visual (sebanyak tujuh indikator) dan dimensi antarmuka situs (sebanyak dua indikator). Selain melihat dari sisi estetika visual dan antarmuka situs, nilai emosional juga dilihat dari kredibilitas dan kepastian situs (Chaffey, EllisChadwick, Mayer, \& Johnston, 2006). Sistematika pengalaman pengguna yang dikemukakan Goddard, McLeary, \& Gorney (2008) bahkan melibatkan interaksi pengguna terhadap konten situs dan persepsi merek situs yang menggambarkan dimensi pengalaman pengguna keseluruhan. Sehingga, eksplorasi pengalaman emosional pengguna yang melibatkan pendekatan non teknis lainnya perlu diperhatikan untuk mengembangkan variabel- variabel yang berkontribusi pada kajian pengalaman emosional pengguna mengakses situs.

Pengujian statistik menggunakan T-test paired-samples memperlihatkan pengalaman emosional pengguna berbeda secara signifikan. Artinya, secara statistik pengalaman emosional pengguna dalam mengakses aplikasi situs di desktop/PC dan perangkat mobile menunjukkan adanya perbedaan respon. Adanya perbedaan respon emosional ditengarai faktor teknis dan ubiquitous. Faktor teknis terdiri dari kesediaan akses (Roto, 2006), piranti lunak (Kaasinen, 2009), visi satu jaringan (Bratt, 2006), sistem komputer (Rabin \& McCathieNeville, 2008), dan penelusur situs (Kane, et al., 2010). Sedangkan faktor ubiquitous dilihat dari data penjualan dan penyebaran perangkat mobile (Avendus, 2013). Pengalaman emosional pengalaman mengakses situs menunjukkan berbeda secara signifikan antara perangkat non mobile dan mobile. Uji perbedaan statistik mengindikasikan adanya perbedaan pengalaman emosional pengguna. Hal ini dipertegas dengan melihat nilai ratarata tiap indikator menunjukkan pengalaman emosional pengguna terhadap situs di kedua perangkat berbeda. Perbedaan nilai rata-rata juga mengindikasikan bahwa respon emosional pengalaman mengakses aplikasi situs pada perangkat non mobile dan mobile pada dasarnya berbeda secara signifikan. Perbedaan pengalaman emosional pengguna ditengarai karena adanya perbedaan secara teknis antara desktop/PC dan perangkat mobile seperti keterbatasan fisik perangkat mobile (Nosrati, Karimi, \& Hassanvand, 2012) dan tampilan visual pada kedua perangkat (Dou, 2013).

Emosional muncul atas bentuk aktualisasi pengalaman-pengalaman 
pengguna berinteraksi dengan aplikasi situs (Desmet, 2012). Uji statistik yang menunjukkan pengalaman emosional pengguna berbeda signifikan atau sama, mengindikasikan emosional pengguna ketika mengakses situs melalui perangkat non mobile dan mobile tidak berbeda jauh. Berdasarkan pendekatan teknis, tampilan visual situs yang ditampilkan dan kemampuan antarmuka kedua bentuk perangkat jelas berbeda. Pada perangkat mobile memiliki berbagai keterbatasan yang tidak memungkinkan pengguna mengakses situs layar penuh, terbatasnya kemampuan perangkat, dan infrastruktur jaringan internet yang tidak stabil. Namun, pengalaman emosional pengguna mengakses aplikasi situs melalui perangkat mobile menunjukkan level yang berbeda juga dengan aplikasi situs layar penuh, lebar, dan jaringan stabil pada tampilan aplikasi situs di perangkat non mobile.

\section{Pengalaman}

mengakses aplikasi situs melalui perangkat terbatas menyebabkan munculnya emosional yang berbeda dengan desktop/PC. Pengalaman terdahulu berupa kebiasaan-kebiasaan, menjadikan pengguna familiar dengan tampilan visual situs berukuran kecil, dengan konten yang terbatas (Lehtonen, et al., 2006). Kebiasaan pengguna mengakses aplikasi situs melalui perangkat mobile dilakukan partisipan setiap hari melalui smartphone dan tablet yang dimiliki masing-masing. Frekuensi mengakses aplikasi situs ini paling banyak dilakukan partisipan diantara 1-5 kali dalam sehari $(78,2 \%)$ dengan durasi mengakses aplikasi situs antara di atas 60 menit $(64,7 \%)$. Hal inilah yang menyebabkan pengguna merasa terdapat perbedaan secara signifikan antara mengakses situsi pada layar besar maupun kecil, dan berbasis perangkat non mobile dan mobile.
Dalam berbagai literatur
mengenai pengalaman pengguna mengakses aplikasi melalui perangkat mobile, user seringkali dihadapkan pada pengalaman negatif karena keterbatasan perangkat yang digunakan. Seperti susahnya menekan tombol tautan pada layar yang kecil, kemudian terbatasnya kapasitas bandwidth perangkat smartphone sehingga gambar atau konten tidak muncul dengan baik. Frustasi maupun kebingungan pengguna mengakses aplikasi melalui perangkat mobile menjadi pengalaman yang harus dijalani pengguna sebagai bagian dari interaksi dengan aplikasi situs (Garrett, 2011). Pengalaman yang dialami secara terus menerus oleh pengguna perlahanlahan menjadi panduan pengguna dalam mengakses aplikasi situs pada perangkat mobile. Pengalaman berinteraksi yang dilakukan pengguna dan aplikasi situs terekam melalui panca indra manusia yang kemudian menghasilkan interpretasi terhadap serangkaian kesulitan dan kemudahan mengakses aplikasi situs mobile. Interaksi pengguna dengan situs yang menghasilkan pengalaman negatif dan positif inilah yang menjadi field of experience. Kemudian rangkaian field of experience inilah yang menjadi pengetahuan pengguna dalam mengakses aplikasi situs dengan istilah self-service (Garrett, 2011).

Pengalaman pengguna secara emosional pada dasarnya dapat dikendalikan dengan melakukan pengawasan pengguna (user monitoring) (Oracle, 2009). Kendali terhadap pengguna dapat dilakukan dengan memperhatikan aspek-aspek yang menjadi determinan munculnya emosional positif atau negatif. Dalam penelitian ini setidaknya terdapat sembilan indikator estetika visual \& antar muka yang dapat menjadi perhatian pengembang aplikasi situs. 
Kemudian dari sisi teknis, kendali terhadap ukuran layar dan tipe keyboard atau layar sentuh juga dapat mempengaruhi emosional pengguna. Sehingga pengalaman emosional yang muncul dapat dikendalikan dengan memperhitungkan aspek gabungan non teknis, seperti visual desain, dan aspek teknis, seperti infrastruktur jaringan dan usabilitas aplikasi situs.

Kendali terhadap emosional pengguna diharapkan memberikan pengalaman positif sesuai dengan jalur yang diinginkan pengembang aplikasi situs yang disebut dengan Key Performance Index (KPI) website (Oracle, 2009). Bentuk kendali yang ditawarkan Oracle adalah dengan melakukan monitoring terhadap aplikasi situs. Monitoring aplikasi situs dilakukan untuk menjaga pengalaman emosional pengguna tetap stabil dan memunculkan pengalaman emosional positif secara konstan. Selain hasil dari pengalaman dan dapat dikendalikan, emosional pengguna terhadap juga dapat diprediksi. Serangkaian perencanaan dan pengembangan aplikasi situs yang terarah mengindikasikan pengalaman pengguna dapat dibangun (Roden, 2010), didesain (Ballard, 2007), diukur secara obyektif (Sauro \& Lewis, 2012) dan diprediksi (Ivory \& Hearst, 2002). Prediksi emosional pengguna terhadap aplikasi situs penting dilakukan dalam media komunikasi berbasis digital (Cockton, 2002). Hal ini penting dilakukan karena komunikasi yang terjadi pada dunia digital terbatas pada bidang afektif (Picard \& Klein, 2002). Sehingga stimulasi emosional melalui tampilan visual, antarmuka dan kemudahan mengakses menjadi penting dilakukan (Kim, Lee, \& Choi, 2003).

Prediksi terhadap emosional pengguna juga dapat memberikan gambaran mengenai tindakan pengguna selanjutnya di masa mendatang, seperti penilaian kredibilitas situs berdasarkan estetika desain situs (Robins \& Holmes, 2008). Dalam konteks yang lebih sempit, pengukuran pengalaman emosional pengguna menggunakan kata sifat bipolar dapat memprediksi ketertarikan pengguna mengakses aplikasi situs yang selanjutnya dapat mendorong pengguna terus mengakses aplikasi situs (Hassenzahl, 2004; Lavie \& Tractinsky, 2004). Sehingga emosional pengguna merupakan aktualisasi pengalaman mengakses aplikasi situs, dan dapat dikendalikan melalui monitoring serta pengukuran akurat yang selanjutnya menjadi prediksi tindakan pengguna terhadap aplikasi situs pada masa mendatang.

\section{Kesimpulan dan Saran}

Penelitian ini membandingkan pengalaman emosional pengguna mengakses aplikasi situs pada perangkat berbeda dengan menggunakan metode eksperimen sehingga menunjukkan adanya perbedaan secara signifikan antara perangkat non mobile dan mobile. Penelitian menghasilkan kesimpulan terkait dengan perbandingan pengalaman emosional pengguna mengakses aplikasi situs pada perangkat non mobile dan mobile sebagai berikut.

Pertama, pengalaman emosional pengguna mengakses aplikasi situs pada perangkat non mobile dan mobile menunjukkan perbedaan yang signifikan. Pengalaman emosional pengguna dalam mengakses aplikasi situs pada perangkat deskptop/PC dan perangkat mobile baik itu smartphone dan tablet menunjukkan adanya perbedaan respon. Ketiga, respon emosional pengguna mengakses aplikasi situs pada perangkat non mobile dan mobile pada dasarnya berbeda signifikan dilihat dari nilai ratarata tiap indikator. Perbandingan nilai rata-rata mengindikasikan adanya 
perbedaan pengalaman emosional. Perbedaan pengalaman emosional pengguna ditengarai karena adanya perbedaan secara teknis antara desktop/PC dan perangkat mobile seperti keterbatasan fisik perangkat mobile dan tampilan visual aplikasi situs pada kedua perangkat. Keempat, sembilan indikator yang teruji valid dan reliabel secara statistik hanya menjelaskan varians lebih dari 50 persen. Sehingga masih ada indikator non teknis lainnya yang belum dijelaskan dari hasil penelitian ini. Masih ada kemungkinan terbentuknya indikator baru yang menjelaskan pengalaman emosional pengguna mengakses aplikasi situs. Selain melihat dari sisi estetika visual dan antarmuka situs, nilai emosional pengguna juga dilihat dari kredibilitas dan kepastian aplikasi situs, interaksi pengguna terhadap konten apliksi situs dan persepsi aplikasi situs yang menggambarkan dimensi pengalaman pengguna keseluruhan. Sehingga, eksplorasi pengalaman emosional pengguna yang melibatkan pendekatan non teknis lainnya perlu diperhatikan untuk mengembangkan variabelvariabel yang berkontribusi pada kajian pengalaman emosional pengguna mengakses aplikasi situs.

Dengan demikian, penelitian selanjutnya dapat menekankan pada aspek perbaikan metodologis baik menggunakan desain penelitian eksperimen murni, pendekatan campuran, metode survei dan replikasi dengan jumlah partisipan ideal. Kemudian pengembangan kajian pengalaman pengguna dalam ranah sosial, khususnya ilmu komunikasi, selanjutnya dapat diarahkan kepada analisis pengguna. Analisis pengguna merupakan kajian serupa analisis khalayak. Sedangkan analisis pengguna merupakan kajian yang berfokus pada pengguna aplikasi situs sebagai implikasi perkembangan teknologi komunikasi berbentuk media baru yang semakin banyak diadopsi dan dimanfaatkan secara umum oleh masyarakat. Aplikasi situs sebagai medium dan media komunikasi baru telah menjadi ubiquitous. Terlebih aplikasi situs saat ini telah menjadi sumber utama informasi bagi pengguna. Sehingga dari aspek teoritis, pengembangan kajian pengalaman emosional pengguna menuju kajian analisis pengguna memiliki signifikansi yang tepat. Pengukuran pengalaman emosional pengguna mengakses aplikasi menuntut pengembangan yang lebih canggih sekaligus lebih sederhana agar dapat diaplikasikan untuk mengevaluasi aplikasi situs yang dikelola. Portal media berita online dan bagian kehumasan memerlukan pengukuran real-time untuk melihat pengalaman emosional pengguna dalam mengakses aplikasi situs. Hal ini dilakukan sebagai evaluasi formatif terhadap program komunikasi yang sedang berjalan. Kemudian dari sisi periklanan dan penyiaran, tampilan iklan dan video di suatu aplikasi situs dapat segera diberikan umpan balik oleh pengguna. Oleh karena itu pengembangan pengukuran pengalaman emosional pengguna terhadap aplikasi situs menjadi perangkat lunak yang tertanam pada setiap aplikasi situs dan diakses secara real-time dapat mempermudah pekerjaan paraktisi komunikasi untuk mengevaluasi media aplikasi situs yang dikelola.

\section{Daftar Pustaka}

Agarwal, A., \& Meyer, A. (2009). Beyond Usability: Evaluating Emotional Response as an Integral Part of The User Experience. HCI (p. 1). Boston: ACM. 
Altermatt, B. (2014). Threats to internal validity for within-subjects designs.

Avendus. (2013). India's mobile Internet $\because$ The revolution has begun. Mumbai: Avendus.

Babbie, E. (2004). The Practice of Social Research 10th Edition. California: Thomson Wadsworth.

Ballard, B. (2007). Designing the Mobile User Experience. West Sussex: Wiley.

Bernhaupt, R., \& Pirker, M. (2013). Evaluating User Experience for Interactive Television: Towards the Development of a Domain-Specific User Experience Questionnaire. Toulouse: IRIT.

Chaffey, D., Ellis-Chadwick, F., Mayer, R., \& Johnston, K. (2006). Internet Marketing:

Strategy, Implementation and Practice. Essex: Pearson Education.

Chernatony, L. d. (2001). Succeeding with Brands on the Internet. Journal of Brand Management, 186.

Cockton, G. (2002). From doing to being: bringing emotion into interaction. Interacting with Computers, 89-92.

Coloma, J. (2012). Development and Validation of the University Website Evaluation Scale (UWES) : A Tool for Assessing Website User Experience on A University Website. Michigan: UMI Publishing.

Crayons, P. (2011, October 11). Retrieved January 14, 2014, from http://designrfix.com/webdesign/website-designs-fail-fix

Deng, L., Turner, D. E., Gehling, R., \& Prince, B. (2010). User Experience, Satisfaction, and Continual Usage Intention of IT. European Journal of Information Systems, 60-75.

Desmet, P. M. (2012). Faces of product pleasure: 25 positive emotions in human-product interactions. International Journal of Design, 129.
Dou, X. (2013). User Experience of Mobile Interactivity: How Do Mobile Websites Affect Attitudes and Relational Outcomes? Michigan: UMI Dissertation Publishing.

eTForecasts. (2006). Internet Users by Country. Retrieved January 13, 2014, from http://www.etforecasts.com/pr/pr10 6.htm

Field, A. (2000). Discovering Statistics using SPSS for Windows. LondonThousand Oaks - New Delhi: Sage Publications.

Garrett, J. J. (2011). The Elements of User Experience: User-Centered Design for the Web and Beyond 2nd Edition. California: Pearson Education.

Irwansyah. (2015). A Bipolar Emotional Response Testing of Online News Website Content . International Journal of Social Science and Humanity, 5 (10), 872-887.

Ivory, M. Y., \& Hearst, M. A. (2002). Improving WebSite Design. IEEE Internet Computing, 58-63.

Kaasinen, E., Roto, V., Roloff, K., Väänänen-Vainio-Mattila, K., Vainio, T., Maehr, W., . . Shrestha, S. (2009). User Experience of Mobile internet - Analysis and Recommendations. Journal of Mobile HCI, IGI Global.

Kaiser, H. (1974). An index of factorial simplicity. Psychometrika, 31-36.

Kane, S., Karlson, A., Meyers, B., Johns, P., Jacobs, A., \& Smith, G. (2010). Exploring Cross-Device Web Use on PCs and Mobile Devices. Washington: Microsoft Research.

Kim, J., Lee, J., \& Choi, D. (2003). Designing emotionally evocative homepages: an empiricalstudy of the quantitative relations between design factors and emotional 
dimensions. Human-Computer Studies, 899-940.

Larson, R., \& Farber, B. (2012). Elementary Statistics: Picturing The World 5th Edition. Boston: Pearson Education.

Lehtonen, T., Benamar, S., Laamanen, V., Luoma, I., Ruotsalainen, O., Salonen, J., \& Mikkonen, T. (2006). Towards User-Friendly Mobile Browsing. ACM, 1.

Logan, R. J. (1994). Behavioral and emotional usability: Thomson consumer electronics. In M. E. Wiklund, Usability in practice: How companies develop user friendly products (pp. 59-82). Boston: Academic Press.

M2 Presswire. (2003, August 4). Omou Ltd: Emotional response testing leads to successful web strategy; Omou Limited launches Bertomo, a non-intrusive site test to create websites that find their target customers. Coventry: Normans Media Ltd.

M2 Presswire. (2012, November 16). American Express Travel Debuts Website Redesign; Refreshed Website Offers a More Personalized, User-Friendly Experience. Coventry: Normans Media Ltd.

Malhotra, N. K. (2004). Marketing Research : An Applied Orientation. New Jersey: Pearson Education.

Meyer, C., \& Schwager, A. (2007). Understanding User Experience. Harvard Business Review, 1-13.

Neuman, L. W. (2006). Social Research Methods : Qualitative and Quantitative Approaches 6th Edition. Boston: Pearson.

Nosrati, M., Karimi, R., \& Hassanvand, H. (2012). Mobile Computing:Principles, Devices and Operating Systems. World Applied Programming, 399-408.
Oracle. (2009). Monitoring The Real User Experience of Oracle EBusiness Suite Users . California: Oracle.

Picard, R., \& Klein, J. (2002). Computers that recognize and respond to user emotion: theoretical and practical implications. Interacting with Computers, 141169.

Rabin, J., \& McCathieNeville, C. (2008, July 29). Mobile Web Best Practices 1.0. Basic Guidelines. Retrieved March 16, 2014, from W3C Recommendation: http://www.w3.org/TR/mobile-bp/

Robins, D., \& Holmes, J. (2008). Aesthetics and credibility in web site design. Information Processing and Management, 386-399.

Roden, T. (2010). Building the Realtime User Experience. California: O'Reilly Media.

Roto, V. (2006). Web Browsing on Mobile Phones: Characteristics of User Experience. Helsinki: Helsinki University of Technology.

Sauro, J., \& Lewis, J. R. (2012). Quantifying the User Experience: Practical Statistics for User Research. Massachussets: Elsevier.

Schaik, P. v., \& Ling, J. (2008). Modelling User Experience with Web Sites: Usability, Hedonis Value, Beauty, Goodness. Interacting with Computers, 419432.

Sellen, A., \& Murphy, R. (2002). The Future of the Mobile Internet: Lessons from Looking at Web Use. Appliance Design, 20-25.

Seltman, H. J. (2013). Experimental Design and Analysis. Pennsylvania: Carnegie Mellon University.

Straubhaar, J., LaRose, R., \& Davenport, L. (2012). Media Now: Understanding Media, Culture and 
Technology 7th Ed. Boston: Wadsworth Cencage Learning.

Swinton, R., \& Kaliouby, R. E. (2012). Retrieved January 13, 2014, from www.affdex.com:

http://www.affdex.com/assets/Meas uring-Emotion-Through-MobileEsomar.pdf

Tarrant, M. A. (2007). Perceived Visual Aestethics of Emotionally Evocative Homepage: An Investigation of Affective Qualities Identified with Emotional Dimension. Indiana: Indiana University.

Timmins, P. J., McCormick, S., Agu, E., \& Wills, C. E. (2006). Characteristics of Mobile Web Content. Worcester: Worcester Polytechnic Institute.

Williamson, I., Lepak, D., \& King, J. (2003). The effect of company recruitment Web site orientation on individuals' perceptions of organizational attractiveness. Journal of Vocational Behavior, 242-263.

Zimmermann, P. G. (2008). Beyond Usability - Measuring Aspects of User Experience. Zurich: Swiss Federal Institute Of Technology Zurich.

Zymbalis, M., Theodorou, M., \& Pavlakis, A. (2008). The Role of Emotions in the Experience of Online Learning: Challenges and Opportunity. Educational media International, 107-117. 